\title{
Theme Based Instruction Model in Teaching Extensive Reading
}

\author{
Mutiarani1), Irpan Ali Rahman'2) \\ 1) Universitas Muhammadiyah Jakarta, Tangerang, Banten, Indonesia \\ 2) Universitas Buddhi Dharma, Tangerang, Banten, Indonesia \\ 1)mutiaranirahman@gmail.com, ${ }^{2)}$ irpanalirahman@gmail.com
}

\begin{abstract}
The purpose of this study is to investigate in detail the implementation of theme based instruction model in teaching extensive reading. This study is classroom action research conducted at the fourth semester students' English Educational Sciences, Educational Sciences Faculty, Universitas Muhammadiyah Jakarta with participant number are 40 students. Data obtained from the result of the test in each cycle. The findings showed that the learning process using theme based instruction model in teaching extensive reading makes the students more participative and active in their classroom reading learning process, it is showed by their high participation during the teaching is increased. Another finding revealed that there is significant influence toward the students' extensive reading learning process from preliminary to cycle II stage in the research process. The average score of students at the preliminary stage is only 68 then it increased to 72 in the first cycle and increased significantly in cycle II with the amount of 83. It can be concluded that classroom action research is done by using of theme based instruction model in teaching extensive reading in the fourthsemester students of English Educational Sciences significantly helps the students in increasing about 21\% improvement from pre-cycle to cycle II in their Extensive Reading course. This study recommends the continuation of using various teaching models for university students to improve their English language skills, especially English reading skill.
\end{abstract}

Keywords: theme based instruction model, extensive reading, English educational sciences students

Citation APA Style: Mutiarani, \& Rahman, I. A. (2019). Theme Based Instruction Model in Teaching Extensive Reading. English Language in Focus (ELIF), 2(1), 43-52.

\section{INTRODUCTION}

$\mathrm{E}$ nglish has become one of the communication media that bridges language and cultural differences in the international world. The ability of foreign languages as a communication tool is what requires students to master English both oral and written including the ability to listen, read, write and speak. The ability to read becomes very important in enriching knowledge and insight in various fields such as politics, diplomacy, international trade, sciences and technology, education, mass media, informational technology, and popular culture. Therefore, the ability to read 
English discourse is very important in supporting four aspects of English language proficiency.

In the English Language Study Program, Faculty of Education at Muhammadiyah University of Jakarta, students are equipped with prerequisite courses, one of which is sharpening reading skills including Basic Reading, Intensive Reading, and Extensive Reading. Extensive reading courses are courses for the ultimate reading competency given in the fourth semester. In these courses, they are not only required to be proficient in understanding English discourse but are also able to choose English reading material from various scientific sources so as to be able to enrich their mastery of vocabulary and general knowledge in various fields.

In fact, the activity of reading English texts has not become a habit in their daily activities, the activities of reading English texts have only become learning the material in formal lectures so that they are not too enthusiastic to choose reading material and understand its contents. This condition is very contrary to the nature of Extensive reading learning activities which focus on reading as much reading material as possible and choosing the reading material according to the interests of the reader. Extensive reading learning not only engages students with reading material but also enriches their experience of vocabulary, reading information, motivation, and experience.

In essence, reading is not only about maximizing vocabulary mastery, but in the end, the learner can gain meaningful experience through the reading process. According to Mikeladze (2014, p. 1), reading is always a meaningful activity with a goal that involves the reader's feelings, knowledge and experience. In the end, reading activities can unite intentions and interests of readers so that the process of transfer of meaning from mind to mind between the reader and writer can be intertwined to create meaningfulness in reading activities. This goal is also expected to be achieved in Extensive reading.

Messaoudi (2013) explains that The Extensive Reading Foundation (ERF) provides a reference namely Guide to Extensive Reading that directs students to read according to graded readers rather than authentic reading material (newspapers, magazines, novels for natives) to the achievement of certain targets. In the end, Extensive Reading does not only focus on reading material but also on achieving targeted reading levels. Mikeladze (2014, p. 34) stated that the target level in Extensive Reading includes beginner to advanced level. At each level will refer to the grammatical structures and vocabulary items appropriate to the level of study so that the reader is able can master several specific English vocabulary adjusted to the specified reading target.

The lack of interest in reading students results in the difficulty of creating learning to read on the ideal and meaningful Extensive Reading subject. A learning model that can integrate structured actual reading topics so that students can practice sorting reading materials according to their interests is needed so that they can achieve the specified learning targets. Extensive 
Reading is expected to be able to improve students' abilities in understanding and communicating important issues in various fields such as education, technology, economy, environment, politics, etc. so that students will be able to use their knowledge related to national and international issues in various fields that link language skills and content.

One learning model that is expected to be able to improve reading skills in Extensive Reading courses by correlating language skills and content is the theme-based instruction model (TBI). TBI model is a learning model that will be used in classifying certain reading material themes related to current issues in developing Extensive Reading learning materials. It focuses on improving reading comprehension achievement in Extensive Reading. The TBI model is one kind of communicative method in teaching the reading comprehension that integrates with the listening, speaking and writing skills.

Based on the explanation above, this study focuses on implementing theme based instruction model (TBI) in teaching Extensive reading at the fourth semester students' English Educational Sciences, Education Faculty, Universitas Muhammadiyah Jakarta. The purpose of this study to examine the implementation of theme based instruction model (TBI) in teaching Extensive reading. The choose of the fourth semester students' English Educational Sciences, Education Faculty, Universitas Muhammadiyah Jakarta as the main object for this research considering some reasons such as students readiness, students uniqueness, and reading skills as Undergraduate students.

\section{Theme Based Instruction Model}

Theme-based instruction model is a learning model that classifies reading topic areas as learning the material in Extensive Reading so that the learning process can later correlate students' English skills with the information contained in the reading material they choose based on interest at the level of advanced readers. Brown in Tsai (2010, p. 78) defined that the theme-based instruction model is arranged around the topics or themes. There are some important principles on theme-based models containing spontaneously, significant learning, inherent motivation, and communicative competence. The main purpose of TBI is to help students in developing their second language competence within specific topics or thematic areas. The theme-based instruction model is mainly applied in adult schools, language institutions, and low to advanced learners.

Cameron in Fristiara \& Rahmawati (2017) stated that themebased instruction model can be integrated in the other material builds on topics and context that are relevant to learners. This approach makes students easy to understand the material because the context of material and the topic link each other. According to Said, Sihes, \& Yusof (2018) explained that theme-based instruction model is highly effective in EFL class context. TBI becomes a very complex communicative method in teaching English reading materials which are integrated to the other language 
skills such as the listening, speaking and writing skills.

In summary, TBI model is the teaching model of language skill and content with the specific language teaching goals. TBI helps the lecturer to develop authentic English reading materials related to the students' interest and needs. In Extensive Reading class is designed to teach about some specific topics in a foreign language to be the base of language skills and content.

\section{The Importance of Theme Based Instruction Model in Language Learning}

Tessier \& Tessier (2015, p. 2) revealed there were some benefits of a theme based instruction model. TBI model expresses fastly in adopting this model in teaching and learning to be the lesson guide. Then it can combine data evidence in the literature regarding the supposed benefits of teaching thematically as the guidelines of thematic teaching model. It reveals how using thematic teaching described obstacles for implementing these guidelines of the instructional, curricular, and organizational levels. It is also as superficially applied themes or topics without strong integration into the study subject and specific objectives and activities connected to the theme. Finally, it can investigate the teaching model, and teaching assessment as the impact of thematic teaching on student success.

There is some benefit of Extensive reading. First, it can improve world knowledge. Second, it can enrich vocabulary mastery. Third, it brings good reading habit as a lifelong activity. Fourth, it builds vocabulary and grammar structure. Fifth, it can enhance comprehension skills. Sixth, it promotes self motivation. Seventh, it encourages students to read fluently with various reading strategies. Eighth, it encourages students progress in language focus and content. Finally, it provides an enjoyable reading experience.

\section{The Implementation of Theme Based Instruction Model in Teaching Extensive Reading}

Palmer in Mikeladze (2014, p. 23) defines extensive reading means rapid reading. The reading activities can read texts written in the foreign language with understanding and without that process of mental translation, referring to the dictionary frequently. It means extensive reading gives a broad chance to read as many as possible and as fast as possible.

Hedge in Mikeladze (2014, p. 24) defines extensive reading with particular characteristics as follow: 1). Having large quantities of reading material such as short stories and novel, newspaper and magazine articles, or professional reading; 2). reading longer texts, 3) reading for general meaning, primarily for pleasure, curiosity, or professional interest and 4). reading longer texts during class time but keep in independent reading at home with selfselected reading materials.

In addition, Kjeldgaard (2015, p. 15) elaborated some principles in Extensive Reading; 1). The number of articles on various topics or themes, 2). Interesting and appropriate level for the articles learning option, 3). The reading goal is to get general knowledge and pleasure, 4). Doing depth analysis and translation to gain the information, 5). 
Giving comment and feedback for weekly tasks and 6). Be brave reading without a dictionary.

Another opinion, Guo in Wafula, Barasa, \& Agalo (2017, p. 5) explained there are the options of authentic reading material for Extensive Reading class, as follow:

1. Graded Readers point at the texts available by major publishers such as Cambridge University Press, Heinemann, Oxford, Penguin, and Macmillan publishers.

2. Texts on the same topics involve reading more than one text on the same topic. They allow for the transfer of background knowledge from one text to another.

3. Authentic materials include reading materials such as newspapers and magazines, which are related to the second language culture of the language learners.

4. Website resources as digital authentic reading materials.

5. Stories and articles which bring different knowledge of text types from their mother language.

Reading materials for extensive reading refer to texts that learners read for pleasure. They are a good source of language input and assist learners to acquire language skills. When choosing Materials for extensive reading, the simplicity and authenticity of the text should be considered. Lecturers play an important role in guiding learners on the kinds of reading materials to choose. They should guide learners through progressively challenging reading materials. TBI model according to Suwannoppharat \& Kaewsa-ard (2014, p. 118) stated that a set of instructional material designed based on the principles called as Six-T (Themes, Texts, Topics, Tasks, Thread, and Thread). In this study, the writer focuses on authentic reading materials for Extensive Reading contain Graded readers, Texts, Authentic materials, Website source and Stories which are related to the second language culture of the language learners. Those reading materials were designed under the theme of 'World Story in Globalization Era' designed seven contents (Politics, Economics, Social, Culture, Education, Defense and Security, Technology). Those texts must be appropriate with the language focus.

The texts learned and practiced the academic content they have to face in their real lives and skills necessary for their study in the academic content. In consequence, the sub-topics of each topic used in the instructional material arranged to support the language performance of each meeting. All subtopics appeared in the extensive reading as the content that is linked to each other to present the connection of academic reading, writing skills and speaking skills used in real academic situations.

Furthermore, the activities designed in each lesson supported both content and language learning by encouraging the subjects' interaction with each other. In this situation, teaching extensive reading is not about boring mechanism but attractive teaching model by integrating language skill with authentic reading content. 


\section{RESEARCH METHODOLOGY}

$\mathrm{T}$ his study uses classroom action research to know the progress of the students' Extensive reading subject using TBI model. The participant of this study is 40 students of fourth semester in academic year 2018/2019. Mettetal (2001) explained that classroom action research is a very effective way to improve the teaching and learning process. It helps lecturer to assess the students' learning progress at mid-term. Then it becomes the hint to plan the most effective strategies for the next of the semester. Comparing the student learning outcomes of different teaching strategies helps to discover which teaching model is appropriate.

CAR provides the form for documenting the teaching and learning objectives. The brief reports resulting from CAR can be included in teaching and learning portfolios. This information can also help to meet the demand requirements of the assessment progress on student learning records. CAR offers a renewed sense of excitement about teaching and learning process after a lack of meaningful teaching and learning process. As a result, CAR methodology provides a new challenge, and the results of CAR projects often prompt the lecturer to change their current teaching strategies.

The participants of this research are in the fouth semester students of English Educational Sciences, Educational Sciences Faculty, Universitas Muhammadiyah Jakarta. The writer focuses on integrating language focus and authentic reading content in Extensive Reading Class. The stages in doing this classroom action research including Planning, Acting, Observing and Reflecting.

\section{FINDING AND DISCUSSION}

B ased on the data analysis, there are three important findings of this classroom action research, it can be explained as follow:

\section{Pre-Cycle Phase}

For this cycle, before implementing theme based instruction model (TBI), the writer collecting student Extensive Reading's score in Extensive Reading class. Based on the students' score, the average students score for precycle is 68. And the lowest score is 66 with the highest score is 70 . It means the learning process is not effective so far, that's why the writer wants to implement to TBI model to teach Extensive Reading class. The successful criterion of this research is when the students get an average score of 80 . The writer starts with planning, observing, acting and reflecting as the phase-in classroom action research.

In Pre-cycle finding revealed that the problem that appeared in Extensive Reading class, the problems are detected as less of enthusiastic, passive learning process, and less of meaningful learning process. Most of the students have weak vocabulary mastery and structure awareness. Those matters have a great impact in the unsuccessful learning process in reading comprehension skill in Extensive reading class.

\section{Cycle Phase I}

Cycle phase I is the first cycle of this research, the finding of the cycle I indicating the improvement of reading comprehension skill in Extensive 
Reading class. The students' scores increased as the average score is 72 and the lowest score is 69 and the highest score is 75 . There is an increase but not a significant one in cycle 1 . This cycle is the first time in implementing TBI model on Extensive Reading class. Therefore to gain better improvement of the students' scores of reading comprehension skill, the writer needs to have the next cycle.

In the first cycle phase, students start to have more enthusiastic and also motivation, and they also enjoy the learning process using TBI model actively. This can be explained as their interaction during the lesson is increased. Totally different from the precycle phase, where the students have lack of motivation, in this cycle they begin to have self confidence. Another finding of the first cycle, the students start to presents good language performance and content as the result of their report of authentic reading materials. They have good better progress on vocabulary building and structure awareness. This situation creates a more meaningful reading class than before.

\section{Cycle Phase II}

The Second Cycle is the last cycle of this research, the score of students increased significantly. The students' average score is 83 with the lowest score is 80 and the highest score is 86 . The result of the second cycle showed the successful process of Extensive reading using TBI model. The students become more active and have better motivation in the learning process. They master various vocabularies and language structure. They own a lot of general knowledge in various fields. In this final cycle, the implementation of TBI model on extensive reading created a successful goal and meaningful learning process.

In this second cycle can be concluded that the additional cycle no needed for this research, the average score gain by the students is 83 means the goal of the lesson is fulfilled. Second cycle finding also revealed great language skills and content as totality of language performance. From all the cycle phases, begins with pre-cycle, first cycle and second cycle can be drawn the analysis that students skill from precycle to cycle II is increased by the implementation of TBI model on extensive reading. The amount of improvement from the pre-cycle to cycle I is $6 \%$ from 68 to 72 of pre and first cycle. Next, the amount of improvement from cycle I to cycle II is $15 \%$ from 72 to 83 of the first and second cycle. The total amount of improvement student English skill is $21 \%$ from pre-cycle till the last cycle of research process. The improvement of extensive Reading score is proof that the research successful in improving students' reading comprehension skills in Extensive Reading class. The following table showed the improvement from pre cycle, cycle I, cycle II in implementation TBI model on Extensive reading:

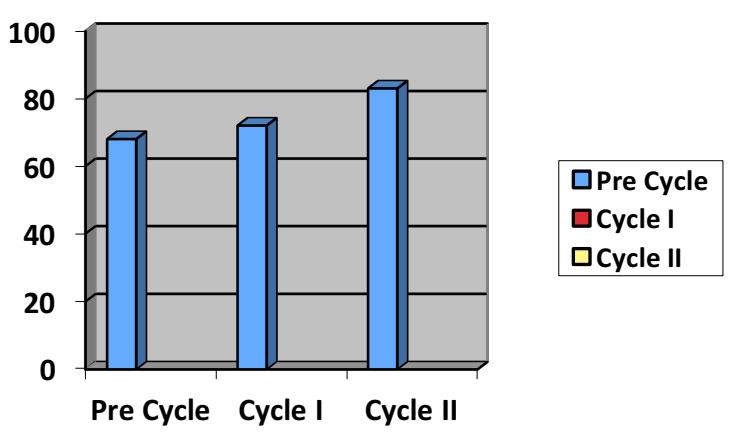

Table 1. The improvement of pre cycle, cycle I, and cycle II in Extensive Reading through TBI model 


\section{CONCLUSION}

he implementation of theme
based instruction model on
extensive reading in the fourth semester students of English Educational Sciences, Education Faculty, UMJ is succeeded in improving the students' score from pre-cycle till the last cycle of the research process. The successful of TBI model in teaching Extensive reading also solve the students' problem such as lack of enthusiastic, lack of motivation and language performance. The students are participated actively in meaningful Extensive reading class. This research is one of the alternative ways that can be used by the lecturer to create meaningful reading comprehension skill in extensive reading class. The study also builds students' self motivation in language performance with thematic reading materials as the actual current issues in the world of globalization era.

In this study, other findings showed that the students in Extensive reading class had better world knowledge and self motivation in language performance. They showed the progress of vocabulary mastery and grammatical structure so they can improve their language focus and content. Hopefully, this meaningful learning process will keep reading habits to be their lifelong activity.

\section{REFERENCES}

Fristiara, C., \& Rahmawati, R. (2017). The Use of Theme-Based Approach in Teaching Young Learners' Vocabulary of English Club at Nur Hidayah Islamic Elementary School. The 2nd TEYLIN International Conference Proceedings April 2017. Retrieved from http://eprints.umk.ac.id/7007/13/

The-2nd-TEYLIN-ilovepdfcompressed-111-117.pdf

Kjeldgaard, M. (2015). Combining SkillsBased Instruction and Extensive Reading Combining Skills-Based Instruction and Extensive Reading: Using Online Resources to Support a Reading Curriculum. Retrieved from http://dl.icdst.org/pdfs/files3/2bf6 9a7467c10b79ef44688ee0019eb8.p df

Messaoudi, A. (2013). Idioms in Graded Readers. In S. Miles \& M. Brierley (Eds.), Proceedings of the Second World Congress on Extensive Reading September 13-15 (pp. 56-60). Retrieved from https://erfoundation.org/ERWC2Proceedings.pdf

Mettetal, G. (2001). The What, Why and How of Classroom Action Research. Retrieved from J SoTL website: https://www.researchgate.net/publ ication/242179106_The_What_Why _and_How_of_Classroom_Action_Res earch

Mikeladze, T. (2014). Extensive Reading (N. Dogonadze, Ed.). Retrieved from https://www.researchgate.net/publ ication/280878633_Extensive_Readi ng

Said, S. D., Sihes, A. J. Bin, \& Yusof, S. M. (2018). Theme-Based Instruction Method in English Reading Comprehension: Using Makassar Local Culture-Based Curriculum Contents. Journal of Physics: Conference Series, 1028(1), 012098. https://doi.org/10.1088/17426596/1028/1/012098

Suwannoppharat, K., \& Kaewsa-ard, A. (2014). Utilization of ContentTheme-Based Instruction: An Overhaul of English Language Learning for Non-native English Learners. International Journal of 
English Language Education, 3(1), 115.

https://doi.org/10.5296/ijele.v3i1.6 786

Tessier, L., \& Tessier, J. (2015). Themebased Courses Foster Student Learning and Promote Comfort with Learning New Material. Journal for Learning through the Arts, 11(1), 124. Retrieved from http://escholarship.org/uc/item/50 28t6zm

Tsai, Y.-L. (2010). The Impact of ContentBased Language Instruction on EFL
Students' Reading Performance. Asian Social Science, 6(3), 77-85. Retrieved from https://pdfs.semanticscholar.org/52 e1/0e35c1affee9e81f4c1c8396be9a 14106181.pdf

Wafula, L., Barasa, P., \& Agalo, J. (2017). Kinds of Extensive Reading Materials and Their Influence on Learners' Language Skills in Language Classrooms in Kenya. Journal of Educational Policy and Entrepreneurial Research, 4(6), 1-9. Retrieved from www.ztjournals.com 
English Language in Focus (ELIF), 2 (1), 43-52. https://jurnal.umj.ac.id/index.php/ELIF 